Supporting Information for:

\title{
Fluoride-Ion Solvation In Non-Aqueous Electrolyte Solutions
}

Victoria K. Davis, ${ }^{a}$ Stephen Munoz, ${ }^{b}$ Jeongmin Kim, ${ }^{b}$ Christopher M. Bates, ${ }^{b+}$ Nebojša

Momčilović, ${ }^{b}$ Keith J. Billings, ${ }^{a}$ Thomas F. Miller III, ${ }^{b}$ Robert H. Grubbs, ${ }^{b}$ Simon C. Jones ${ }^{a *}$

aElectrochemical Technologies Group, Jet Propulsion Laboratory, California Institute of Technology, Pasadena, California 91109, United States.

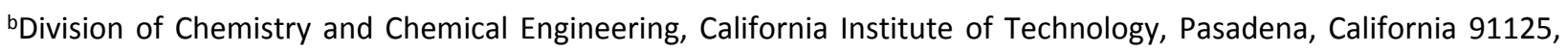
United States.

*Corresponding author: Email: scjones@caltech.edu

†Present address: Materials Department and Department of Chemical Engineering, University of California, Santa Barbara, Santa Barbara, California 93106, United States.

\section{Table of Contents}

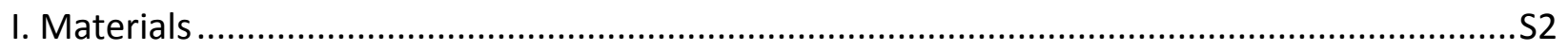

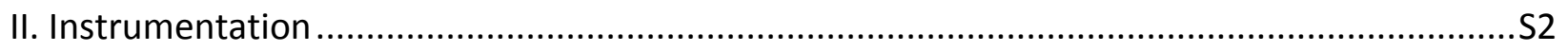

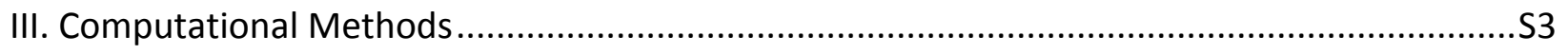

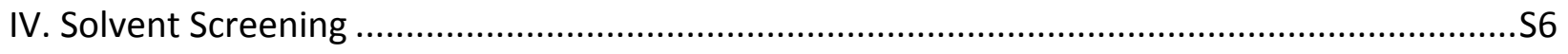

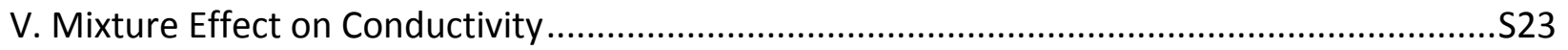




\section{Materials.}

All materials were purchased from Sigma-Aldrich, Alfa Aesar, TCl America, Strem, and/or Fisher and used as-received unless specified otherwise. NMR solvents were purchased from Cambridge Isotope Laboratories, Inc. Dry diethyl ether was obtained via elution through a solvent column drying system ${ }^{1}$ and degassed with argon prior to use. All solvents were dried over $4 \AA ̊$ molecular sieves in either a dryroom or an Ar-filled glovebox, prior to their use with dry fluoride salts in solvent screening studies or conductivity measurements. $\mathrm{H}_{2} \mathrm{O}$ content (ppm) was monitored via Karl Fisher titration until solvents were considered sufficiently dry $\left(\mathrm{H}_{2} \mathrm{O} \leq 150 \mathrm{ppm}\right)$.

\section{Instrumentation.}

Nuclear magnetic resonance (NMR) spectra were obtained using either a Mercury Plus 300, Varian 400, or Inova 500 NMR spectrometer. Chemical shifts for protons are reported in parts per million downfield from tetramethylsilane and are referenced to residual protium in the NMR solvent, $\mathrm{CD}_{3} \mathrm{CN}(\delta$ 1.96). Chemical shifts for fluorine are reported in parts per million and are referenced to deuterated bifluoride signal, $\mathrm{DF}_{2}^{-}(\Phi-147)$.

Ionic conductivities were investigated by AC impedance spectroscopy using a VersaSTAT potentiostat. Measurements were acquired between $100 \mathrm{mHz}$ and $1 \mathrm{MHz}$ using an air-free glass conductivity cell with a Teflon ring sealing the solution between two parallel Pt electrodes $(1 \mathrm{~cm}$ separation). The cell constant was determined before each experiment by measuring the conductivity of an aqueous potassium chloride $(0.1 \mathrm{M})$ solution. Thermal control was provided by a Tenney TUJR chamber, with the sample allowed to reach thermal equilibrium before measurement (as determined by no observed change in the impedance spectrum over time).

\footnotetext{
${ }^{1}$ A. B. Pangborn, M. A. Giardello, R. H. Grubbs, R. K. Rosen and F. J. Timmers, Organometallics, 1996, 15, 1518-1520.
} 


\section{Computational Methods.}

\section{Partial Charges}

Partial charges were acquired via CHELPG calculations on optimized geometries of the molecules at the B3LYP-D3/def2-TZVP level of theory using the ORCA software package. ${ }^{2}$

\section{pKa Values}

pKa values were acquired via the following equation.

$$
p K_{a}=a \frac{\Delta G_{-H}}{R T \ln (10)}+b
$$

where the free energy of deprotonation $\Delta G_{-H}$ was obtained via comparison of the zero-point and thermal corrected electronic energies of neutral and deprotonated species. The B3LYP-D3/madef2-TZVP level of theory was used to optimize the different molecules, first in vacuum, then again using the CPCM continuum solvation model with a dielectric of 47.2 to match DMSO. We then performed frequency calculations on the optimized geometries to obtain the zero-point and room-temperature thermal corrections to the energies. The calibration constants $a$ and $b$ were obtained by fitting reference solvents: cyclopenta-1,3-diene, dimethyl 2(trifluoromethyl)propanedioate, dimethyl propanedioate, 1,1,1,3,3,3-hexafluoro-2(trifluoromethyl)propane, and acetonitrile. Calculations with these specified conditions were performed using the ORCA software package, ${ }^{2}$ and robustness of the results was confirmed for related functionals and parameters using the entos software package. ${ }^{3}$

\footnotetext{
${ }^{2}$ F. Neese, Wiley Interdiscip. Rev. Comput. Mol. Sci., 2012, 2, 73-78.

${ }^{3}$ F. R. Manby, T. F. Miller III, P. J. Bygrave, F. Ding, T. Dresselhaus, F. A. Batista-Romero, A. Buccheri, C. Bungey, S. J. R. Lee, R. Meli, K. Miyamoto, C. Steinmann, T. Tsuchiya, M. Welborn, T. Wiles and Z. Williams, ChemRxiv.7762646, 2019.
} 


\section{Free Energy of Solvation}

Free energies of solvation were obtained via thermodynamic integration in MD simulations, ${ }^{4}$ with scaled Lennard-Jones and Coulomb potentials to gradually introduce ion-solvent interaction contributions to the potential energy, following the protocol previously established. ${ }^{5}$ These simulations were run using the LAMMPS software package. For each solvent, 4 independent initial configurations were prepared, each containing 100 solvent molecules oriented randomly and without a significant overlap. Each system was relaxed in the NVE ensemble with restrained displacements $(0.1 \AA)$ for 30 ps, and then underwent a 1 ns long equilibration in NPT ensemble as the temperature was gradually increased from $100 \mathrm{~K}$ to $298 \mathrm{~K}$. Once at $298 \mathrm{~K}$, the system was allowed to equilibrate for a further 2 ns under NPT condition.

Force field parameters for the solvents were taken from the OPLS-aa parameter set. ${ }^{6}$ CHELPG-generated charge values were substituted in where there was significant disagreement with the OPLS charges (as was the case for BTFE, PN, and 2,6 DFP).

All trajectories are integrated using the velocity-Verlet integrator with a $1 \mathrm{fs}$ timestep and periodic boundary conditions along all directions. The particle-particle-particle-mesh (PPPM) algorithm was used to calculate the long-range contribution of the Coulomb interaction, with Lennard-Jones and Coulomb interaction cutoffs set at $14 \AA$. The Nosé-Hoover thermostat (100 fs relaxation) and the Nosé-Hoover barostat (1000 fs relaxation) were applied in all simulations to control the temperature $(298 \mathrm{~K})$ and the pressure (1 atm). All simulations performed for

${ }^{4}$ D. Frenkel and B. Smit, in Understanding Molecular Simulation: From Algorithms to Applications, Academic Press, San Diego, 2nd edn., 2002, pp. 168-172.

${ }^{5}$ V. K. Davis, C. M. Bates, K. Omichi, B. M. Savoie, N. Momčilović, Q. Xu, W. J. Wolf, M. A. Webb, K. J. Billings, N. H. Chou, S. Alayoglu, R. K. McKenny, I. M. Darolles, N. G. Nair, A. Hightower, D. Rosenberg, M. Ahmed, C. J. Brooks, T. F. Miller, R. H. Grubbs and S. C. Jones, Science, 2018, 362, 1144-1148.

${ }^{6}$ (a) W. L. Jorgensen and J. Tirado-Rives, PNAS, 2005, 102, 6665-6670. (b) L. S. Dodda, J. Z. Vilseck, J. Tirado-Rives, and W. L. Jorgensen, J. Phys. Chem. B, 2017, 121, 3864-3870. (c) L. S. Dodda, I. C. De Vaca, J. Tirado-rives and W. L. Jorgensen, Nucleic Acids Res., 2017, 45, W331-W336. 
calculating the free-energy of solvation employ soft-core Lennard-Jones interactions $(n=1$, $\alpha_{L J=0.5, \text { and }} \alpha_{C=0}$, as implemented in LAMMPS).

Once the systems were equilibrated, a single anion $\left(\mathrm{F}^{-}\right)$or cation $\left(\mathrm{Np} 1^{+}\right)$was inserted into the solvent system. The Lennard-Jones and Coulomb potential energies between the ion and the solvent molecules were gradually scaled up to full interaction potential (initially, both interactions were absent) using

$$
U_{L J}\left(\lambda_{L J}\right)=U_{S}+\lambda_{L J} U_{L J}
$$

Here, $U_{S}$ represents the solvent-only potential term, $\lambda_{L J}$ is the scaling factor for the $\amalg$ potentials, and $U_{L J}$ represents the total solvent-ion Lennard-Jones interaction. Interaction strength was ramped from $\lambda_{L J}=0$ (no interaction) to $\lambda_{L J=1}$ (full interaction), in steps of 0.2 . Once full interaction strength was reached, the Coulomb interaction potential was gradually introduced via scaling of the charges on the ions, following the equation:

$U_{C}\left(\lambda_{C}\right)=U_{L J}(1)+\lambda_{C} U_{C}$

where $\lambda_{C}$ is the scaling factor for Coulomb potentials, and ${ }_{C}$ represents the total solvent-ion Coulomb interaction. Interaction strength was ramped from $\lambda_{C}=0.2$ to 1 in steps of 0.2 (due to a redundant step at $\lambda_{L J=1.0}$ and $\left.\lambda_{C}=0\right)$.

There are then 11 total steps, 6 for the $\amalg$ interaction scaling, and 5 for the Coulomb interaction scaling. At each $\lambda$-step, the system was allowed to equilibrate for $250 \mathrm{ps}$, followed by 250 ps to collect the potential energy. To calculate the solvation free energy $\left(\Delta G_{T I}\right)$, the following equation was used:

$\Delta G_{T I}=\int_{0}^{1}\left(\frac{d U_{L J}}{d \lambda_{L J}}\right) d \lambda_{L J}+\int_{0}^{1}\left(\frac{d U_{C}}{d \lambda_{C}}\right) d \lambda_{C^{\prime}}$ 
where the brackets indicate an ensemble average at each $\lambda_{\text {-step, }}$ and we have made the approximation that the $\mathrm{P} \Delta \mathrm{V}$ contribution to the free energy can be neglected.

The finite difference method was employed to calculate the derivative of the total potential energy at each $\lambda$-step, using forward or backward difference at the endpoints, and central difference at all other points. To do so, total potential energies were calculated at $\lambda=$ \pm 0.01 using the configurations sampled at each $\lambda$-step. With the derivatives complete, we used the trapezoidal rule to numerically integrate them and arrive at the free energy of solvation. For each solvent, free energy of solvation was calculated for $F^{-}$and $N p 1^{+}$, averaging values from the 4 independent initial configurations.

It should be noted that the polyatomic cation carries its own free energy contribution which must be subtracted out to arrive at the correct free energy of solvation. This cation-free energy was determined via a free energy perturbation of $10 \mathrm{~ns}$ in vacuum.

\section{Mixed-Solvent MD Simulations}

All-atom molecular dynamics simulations were carried out to support analysis of the mixture effect on conductivity with co-solvents using a mixture of BTFE solvent and co-solvent molecules, keeping the volume ratio of a solution of neat BTFE to that of neat co-solvent 3:1 with 99 BTFE molecules. Initial configurations were generated, placing BTFE molecules randomly in a simulation box. After a short run (1 ns), co-solvent molecules were introduced in the neat BTFE solution. $\mathrm{Np}_{1} \mathrm{~F}$ salts were added in the mixture after another short run (1 ns).

The OPLS force field, ${ }^{6 a, 6 c, 7}$ a non-polarizable and all-atom model, was used to describe the potential energy functions of all molecules including BTFE, co-solvents, and $\mathrm{Np}_{1} \mathrm{~F}$ salt. Interactions between atoms were described using both electrostatic and Lennard-Jones (LJ)

\footnotetext{
${ }^{7}$ K. P. Jensen and W. L. Jorgensen, J. Chem. Theory Comput., 2006, 2, 1499-1509.
} 
interactions. The cross terms of $\amalg$ interaction were obtained using a geometric mixing rule. Intramolecular interactions were described using harmonic potential energy functions for bonds and angles, and the sum of cosine functions for dihedral angles. All simulations were conducted using the LAMMPS simulation package. ${ }^{8}$

In all cases during both equilibration and production runs, the MD trajectories were integrated using the velocity-Verlet methods with a timestep of $1 \mathrm{fs}$. Both $\mathrm{LJ}$ and Coulomb interactions were cut at $14 \AA$, and particle-particle particle-mesh Ewald summation ${ }^{9}$ was used to compute Coulomb interactions beyond the cutoff distance. Periodic boundary conditions were applied along all directions. The Nosé-Hoover thermostat (100 fs relaxation) and the NoséHoover barostat (1000 fs relaxation) were applied in all simulations to control the temperature (300 K) and the pressure ( $1 \mathrm{~atm})$. All the quantities reported here were averaged using simulation trajectories over $10 \mathrm{~ns}$ after equilibration at least during $5 \mathrm{~ns}$.

Volume-corrected charge mean-squared displacement (MSD), vc-cMSD(t), is calculated via the Einstein relation ${ }^{10}$ as follows:

$\mathrm{vc}-\operatorname{cMSD}(\mathrm{t})=\frac{1}{V} \sum_{i=1}^{N} \sum_{j=1}^{N} z_{i} z_{j}\left\langle\left[\vec{r}_{i}(t)-\vec{r}_{i}(0)\right]\left[\vec{r}_{j}(t)-\vec{r}_{j}(0)\right]\right\rangle$

where $N$ is the total number of ions, $z_{i}$ is charge of $i^{\text {th }}$ ion, $\vec{r}_{i}(t)$ is the position of $i^{\text {th }}$ ion at time $t, V$ is the volume of a mixture, and $\langle\cdots\rangle$ represents the ensemble average. Note that in the simulated nanosecond timescales, vc-cMSD is subdiffusive with respect to time, i.e., $\operatorname{vc}-\operatorname{cMSD}(t) \approx 6 D_{t} t^{\beta}$. The exponent $\beta$ and the time-dependent collective diffusion constant $D_{t}$ were determined via a

\footnotetext{
${ }^{8}$ S. Plimpton, J. Comput. Phys., 1995, 117, 1-19.

${ }^{9}$ R. W. Hockney and J. W. Eastwood, Computer Simulation Using Particles, CRC Press, Boca Raton, 1 st edn., 1988.

${ }^{10}$ Allen, M.P., et al., Computer Simulation of Liquids, Clarendon Press, 1989.
} 
least-square method to fit vc-cMSD $(t)$ in the time window of $(t 1, t 2)$. These parameters were then used to calculate the Green-Kubo conductivity, ${ }_{G K}$ :

$$
\sigma_{G K}=\frac{e^{2} v c-c M S D(t)}{k_{B} T \quad 6 t} \approx \frac{e^{2}}{k_{B} T} D t \frac{t 2^{\beta}-t 1^{\beta}}{t 2-t 1},
$$

where $k_{B \text { is }}$ the Boltzmann constant, $T$ is the temperature of simulated mixtures, $e$ is the elementary charge, and $t_{1}=2 \mathrm{~ns}$ and $t_{2}=6 \mathrm{~ns}$.

This $\sigma_{G K}$ is a collective property that takes ion-ion correlations into account. When all correlations (off-diagonal terms) are neglected, it becomes the same as the Nernst-Einstein conductivity, $\sigma_{N E: 11}$

$$
\sigma_{N E}=\frac{e^{2} 1}{k_{B} T V}\left(z_{+}^{2} N_{+} D_{+}+z_{-}^{2} N_{-} D_{-}\right)=\frac{e^{2} 1}{k_{B} T V} N\left(D_{+}+D_{-}\right)
$$

where + and - represent $N p_{1}^{+}$and $F^{-}$ion, respectively, ${ }^{z_{+}}=-z_{-}=1$, and $N=N_{+}=N_{-}$. In all cases but one, the self-diffusion coefficient $(D)$ for the ionic species and solvent molecules was calculated using the Einstein relation:

$M S D(t)=6 D t$.

In the BTFE:DMBA mixture, the MSD of both ionic species is subdiffusive on the simulated timescales; consequently, D for the ionic species in this mixture was estimated via the leastsquare fitting of the MSD, $\operatorname{MSD}(t) \approx 6 D_{s} t^{b}$, in a time window of $\left(t_{1}, t_{2}\right)$, using

$$
D=\frac{M S D(t)}{6 t}=D_{s} \frac{t 2^{b}-t 1^{b}}{t 2-t 1},
$$

where $t_{1}=2 \mathrm{~ns}$ and $t_{2}=6 \mathrm{~ns}$.

\footnotetext{
${ }^{11}$ A. France-lanord and J. C. Grossman, Phys. Rev. Lett., 2019, 122, 1-6.
} 


\section{Solvent Screening.}

Table S1. Solubility information and NMR characteristics of $\mathrm{Np}_{1} \mathrm{~F}$ dissolved in various organic solvents.

\begin{tabular}{|c|c|c|c|c|c|c|}
\hline Entry & Solvent & Structure & $\begin{array}{c}\text { Approx. Solubility } \\
\text { (mol } \mathrm{Np}_{1} \mathrm{~F} / \\
\text { L solvent) }\end{array}$ & $\begin{array}{l}\text { F- Chemical } \\
\text { Shift (ppm) }\end{array}$ & $\begin{array}{l}\text { F- Peak Width } \\
\text { at Half Height } \\
\qquad(\mathrm{Hz})\end{array}$ & $\begin{array}{c}\mathrm{HF}_{2}^{-} \\
\text {Chemical } \\
\text { Shift (ppm) }\end{array}$ \\
\hline 1 & Acetonitrile (AN) & & 2.18 & -74.18 & 21.52 & -146.60 \\
\hline 2 & $\begin{array}{l}\text { 2,3-Difluorobenzonitrile } \\
\text { (2,3-FBN) }\end{array}$ & & 0.40 & $-{ }^{a}$ & - & $-146.61^{b}$ \\
\hline 3 & $\begin{array}{l}\text { 2-Fluorobenzonitrile (2- } \\
\text { FBN) }\end{array}$ & & 0.12 & $-^{a}$ & - & - \\
\hline 4 & $\begin{array}{l}\text { 3-Fluorobenzonitrile (3- } \\
\text { FBN) }\end{array}$ & & 0.19 & $-a$ & - & - \\
\hline 5 & $\begin{array}{l}4,4,4- \\
\text { trifluorobutyronitrile } \\
\text { (TFBN) }\end{array}$ & & 0.10 & -120.39 & 73.13 & $-146.60^{c}$ \\
\hline 6 & Propionitrile (PN) & & 0.07 & -106.08 & 38.07 & - \\
\hline 7 & $\begin{array}{l}\text { (Dimethylamino)acetonit } \\
\text { rile (DMAAN) }\end{array}$ & & 0.14 & -75.36 & 104.09 & $-146.62^{b}$ \\
\hline 8 & $\begin{array}{l}\text { Methoxyacetonitrile } \\
\text { (MeOAN) }\end{array}$ & & 0.80 & -84.25 & 47.90 & -146.39 \\
\hline 9 & $\begin{array}{l}\text { 3-Methoxypropionitrile } \\
\text { (MeOPN) }\end{array}$ & & 0.78 & -126.61 & 27.22 & -146.36 \\
\hline 10 & $\begin{array}{l}\text { 2,6-Difluoropyridine (2,6- } \\
\text { DFP) }\end{array}$ & & 0.39 & -76.12 & 24.58 & - \\
\hline 11 & $\begin{array}{l}\text { Phenyl trifluoroacetate } \\
\text { (PhTFA) }\end{array}$ & & 0.47 & $-{ }^{d}$ & - & $\begin{array}{c}-147(\mathrm{bs})^{e} \\
{[15.88]^{f}}\end{array}$ \\
\hline 12 & $\begin{array}{l}\text { Fluoroethylene } \\
\text { carbonate (FEC) }\end{array}$ & & 0.71 & $-^{a}$ & - & $\begin{array}{c}-147(\mathrm{bs})^{e} \\
{[14.97]^{f}}\end{array}$ \\
\hline 13 & $\begin{array}{l}\text { 2,2,2-Trifluoroethyl } \\
\text { trifluoroacetate (TFE- } \\
\text { TFA) }\end{array}$ & & 0.95 & $-^{a}$ & - & -146.61 \\
\hline 14 & $\begin{array}{l}\text { Bis(2,2,2-trifluoroethyl) } \\
\text { carbonate (BTFC) }\end{array}$ & & 0.19 & $-^{a}$ & - & -146.50 \\
\hline 15 & $\begin{array}{l}\text { Bis(2,2,2-trifluoroethyl) } \\
\text { ether (BTFE) }\end{array}$ & $\mathrm{F}_{3} \mathrm{C} \widehat{\mathrm{O}}$ へ $\mathrm{CF}_{3}$ & 2.23 & -71.94 & 25.13 & - \\
\hline 16 & $\begin{array}{l}\text { Tris(2,2,2-trifluoroethyl) } \\
\text { phosphite (TTFP) }\end{array}$ & 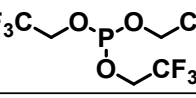 & 1.05 & $-a$ & - & - \\
\hline
\end{tabular}

${ }^{a}$ Not assigned due to multiple new peaks. ${ }^{b} \mathrm{HF}_{2}{ }^{-}$signal is not representative of $\mathrm{F}^{-}$reaction with solvent; solvent used for screening was not fully dried. ${ }^{C} \mathrm{No} \mathrm{DF}_{2}{ }^{-}$detected; $\mathrm{HF}_{2}{ }^{-}$peak referenced to $-146.60 \mathrm{ppm}$. ${ }^{d}$ No $\mathrm{F}^{-}$peak detected. ${ }^{e}$ Broad singlet in the ${ }^{19} \mathrm{~F} \mathrm{NMR}$ where $\mathrm{HF}_{2}{ }^{-}$and $\mathrm{DF}_{2}{ }^{-}$overlap. ${ }^{f} \mathrm{HF}_{2}{ }^{-}$signal detected in the ${ }^{1} \mathrm{H} \mathrm{NMR}$. 


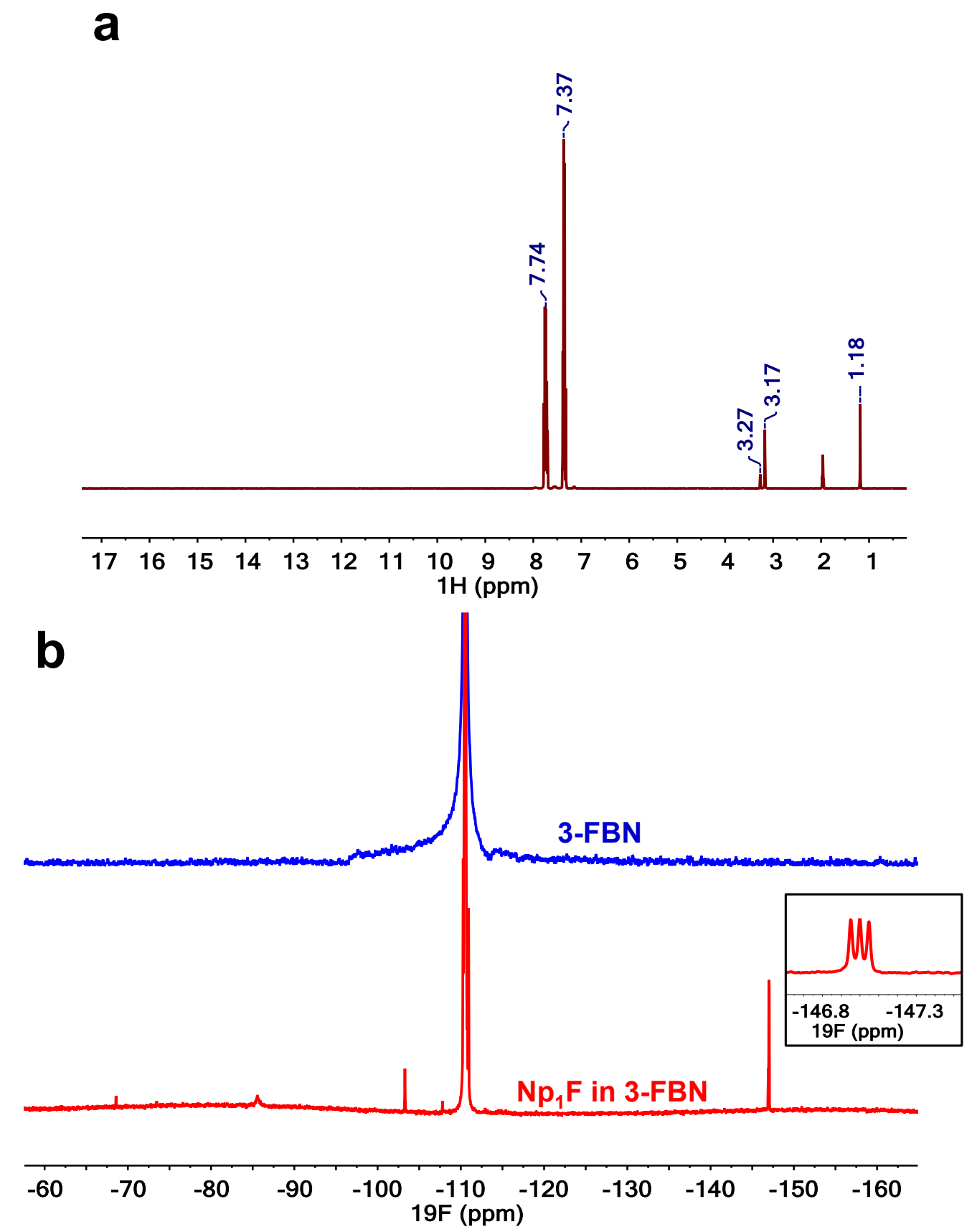

Figure S1. (a) ${ }^{1} \mathrm{H} N M R\left(\mathrm{CD}_{3} \mathrm{CN}\right)$ of 3-fluorobenzonitrile with $\mathrm{Np}_{1} \mathrm{~F}(0.19 \mathrm{M})$. (b) ${ }^{19} \mathrm{~F} \mathrm{NMR}\left(\mathrm{CD}_{3} \mathrm{CN}\right)$ of 3-fluorobenzonitrile without $\mathrm{Np}_{1} \mathrm{~F}$ (blue) and 3-fluorobenzonitrile with $\mathrm{Np}_{1} \mathrm{~F}$ (red). 

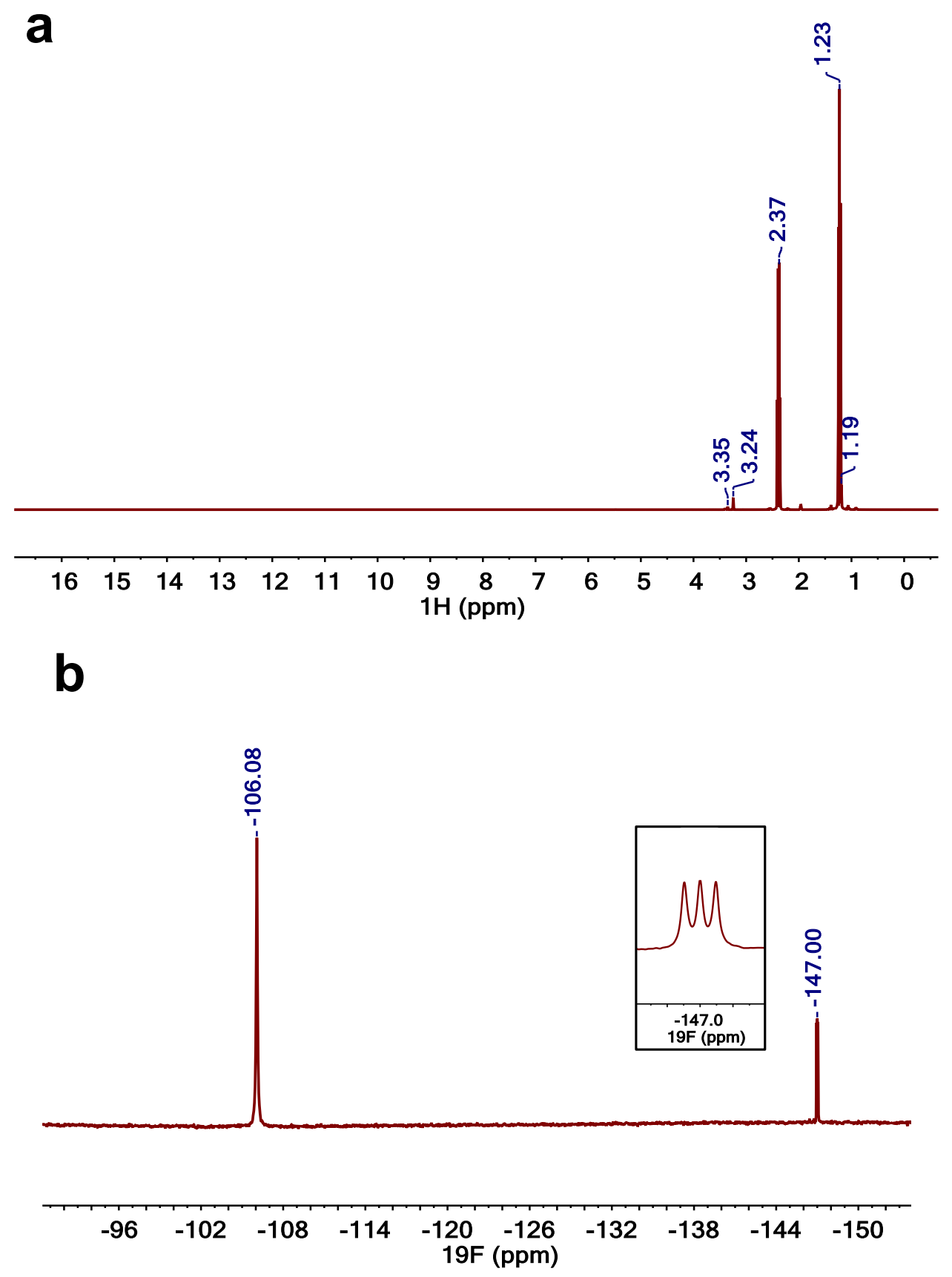

Figure S2. (a) ${ }^{1} \mathrm{H} N M R\left(\mathrm{CD}_{3} \mathrm{CN}\right)$ and (b) ${ }^{19} \mathrm{~F} \mathrm{NMR}\left(\mathrm{CD}_{3} \mathrm{CN}\right)$ of propionitrile with $\mathrm{Np}_{1} \mathrm{~F}(0.07 \mathrm{M})$. 


\section{a}
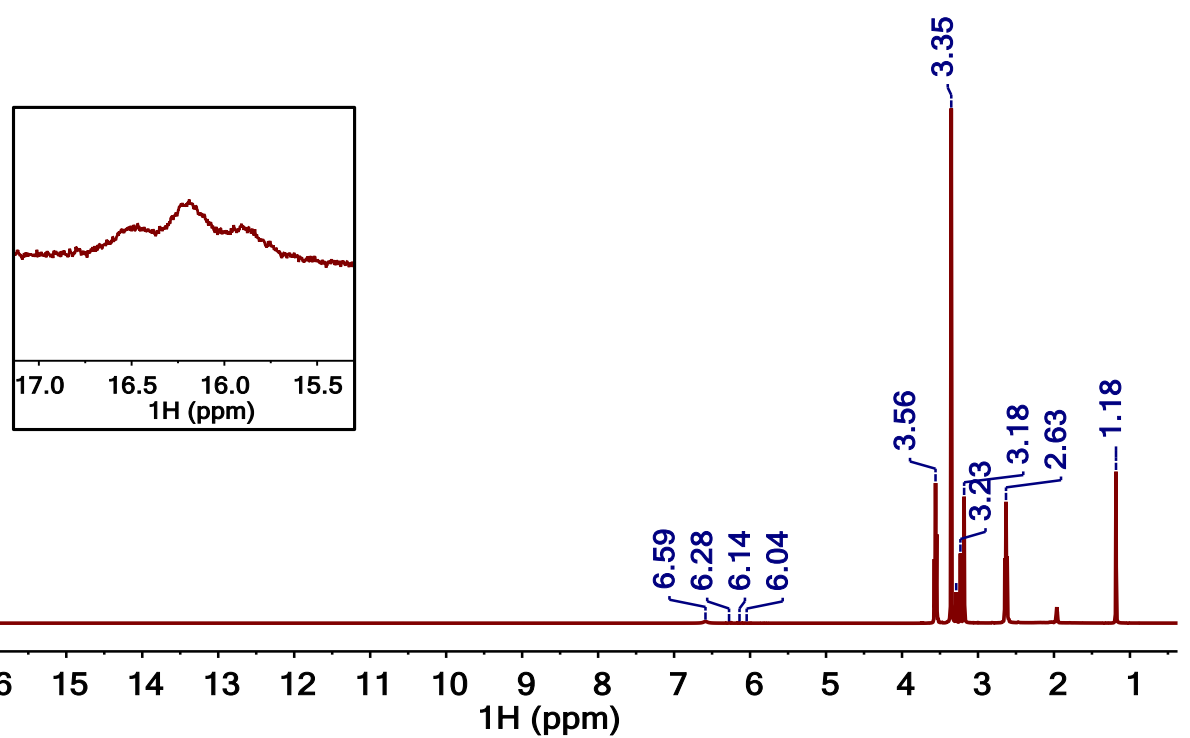

b

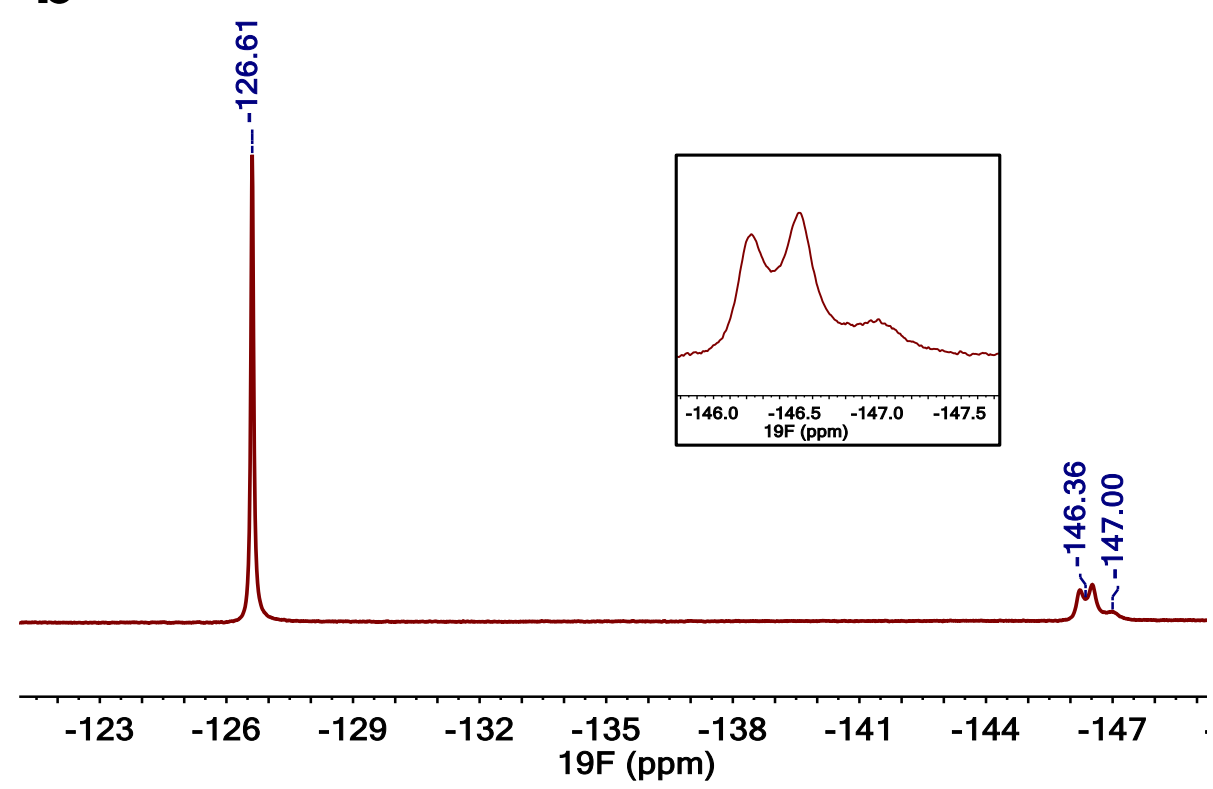

Figure S3. (a) ${ }^{1} \mathrm{H} N M R\left(\mathrm{CD}_{3} \mathrm{CN}\right)$ and (b) ${ }^{19} \mathrm{~F} \mathrm{NMR}\left(\mathrm{CD}_{3} \mathrm{CN}\right)$ of 3-methoxypropionitrile with $\mathrm{Np}_{1} \mathrm{~F}$ $(0.78 \mathrm{M})$. 

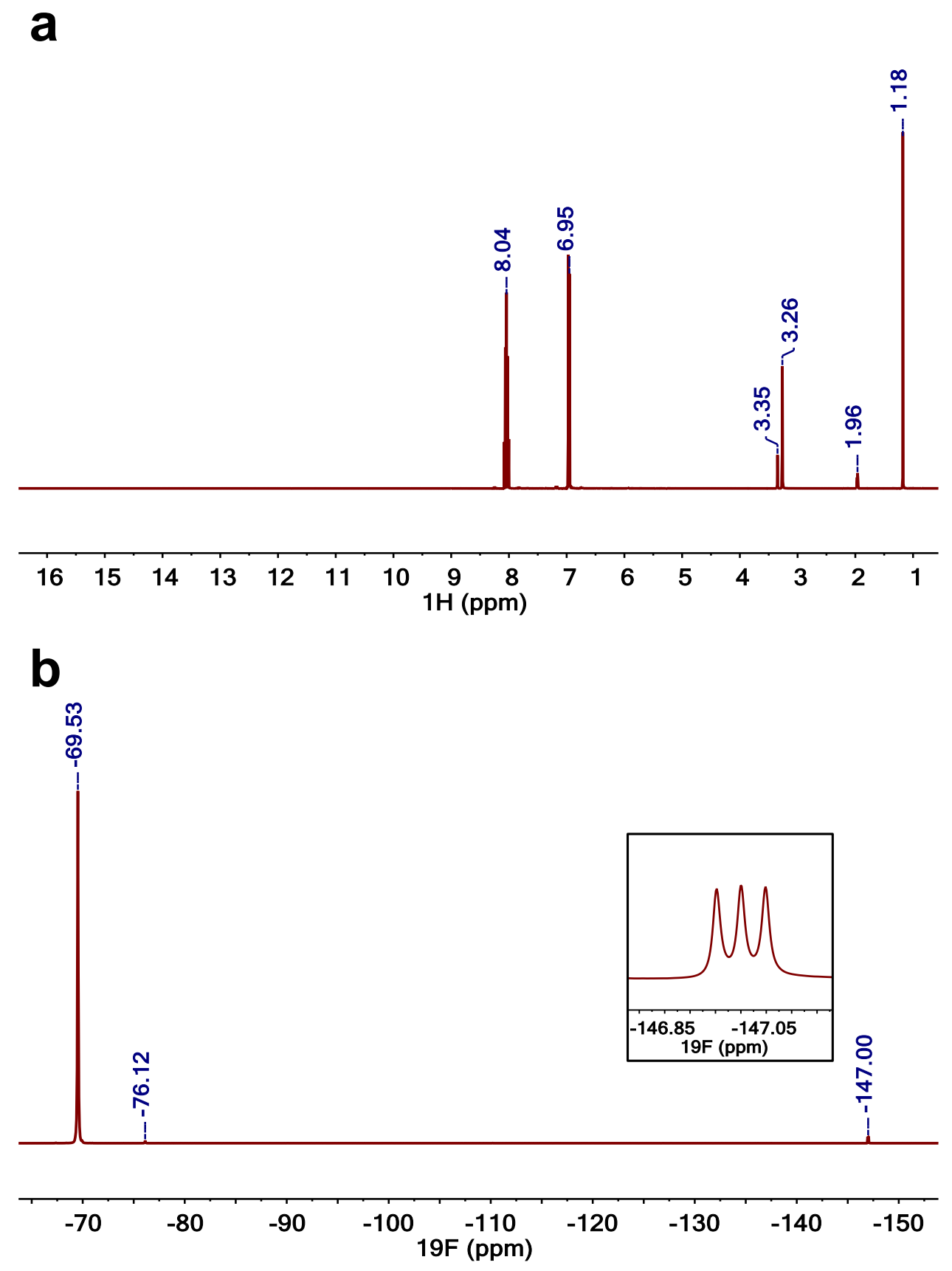

Figure S4. (a) ${ }^{1} \mathrm{H} N M R\left(\mathrm{CD}_{3} \mathrm{CN}\right)$ and (b) ${ }^{19} \mathrm{~F} \mathrm{NMR}\left(\mathrm{CD}_{3} \mathrm{CN}\right)$ of 2,6-difluoropyridine with $\mathrm{Np}_{1} \mathrm{~F}(0.39$ $\mathrm{M})$. 

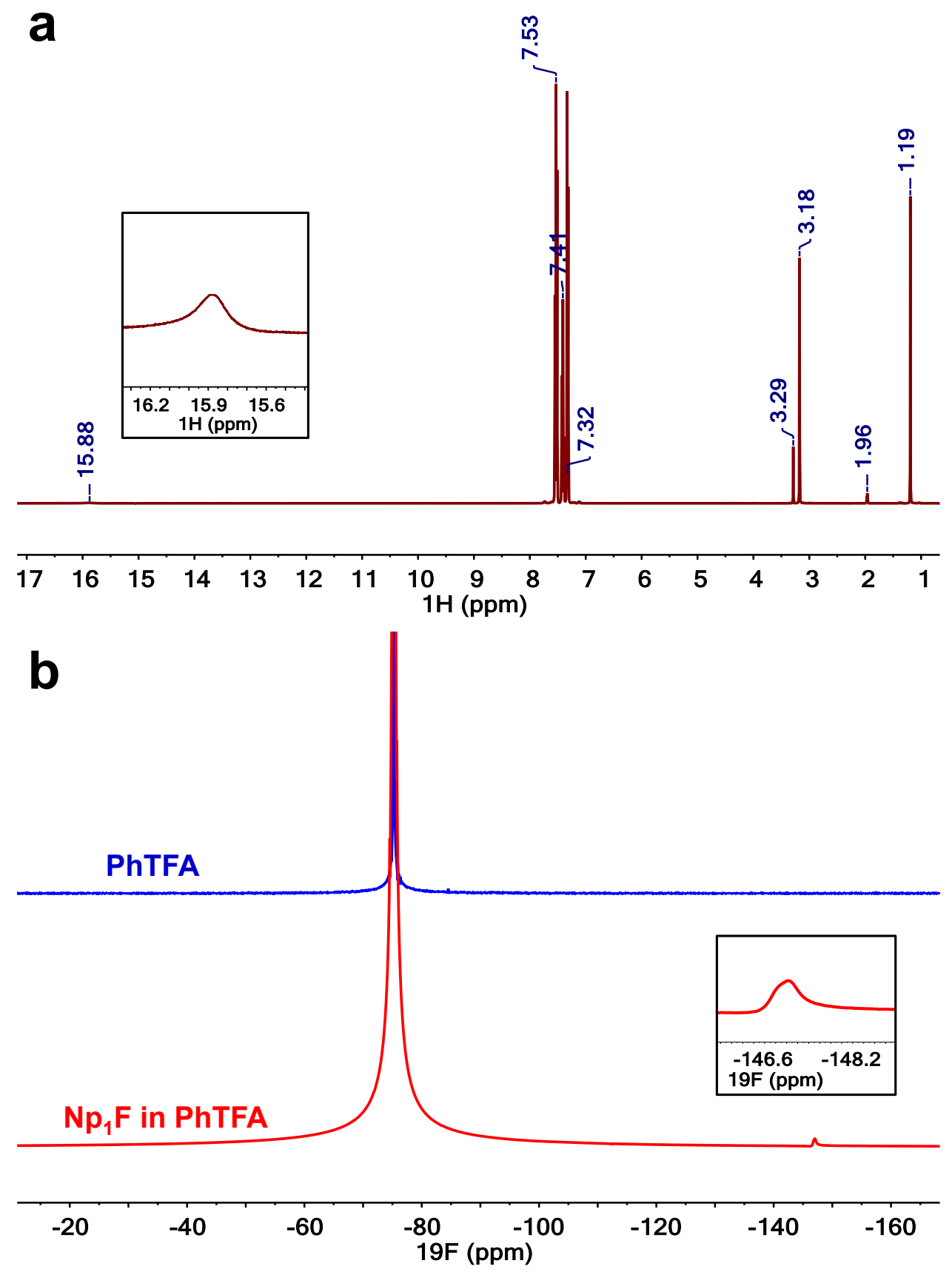

Figure S5. (a) ${ }^{1} \mathrm{H} N M R\left(C_{3} \mathrm{CN}\right)$ of phenyl trifluoroacetate with $\mathrm{Np}_{1} \mathrm{~F}(0.47 \mathrm{M})$. (b) ${ }^{19} \mathrm{~F} N \mathrm{NR}$ $\left(\mathrm{CD}_{3} \mathrm{CN}\right)$ of phenyl trifluoroacetate without $\mathrm{Np}_{1} \mathrm{~F}$ (blue) and phenyl trifluoroacetate with $\mathrm{Np}_{1} \mathrm{~F}$ (red). 

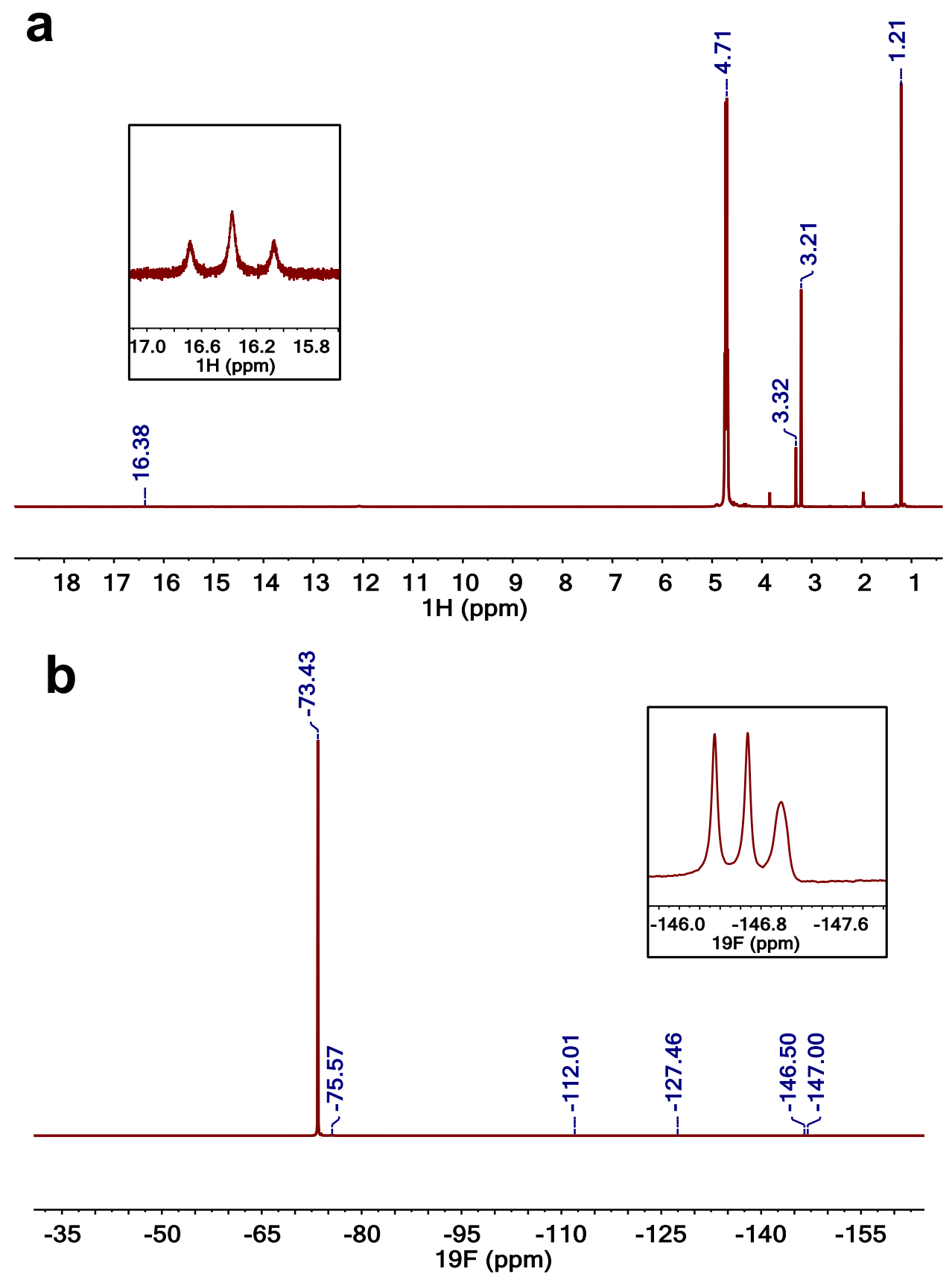

Figure S6. (a) ${ }^{1} \mathrm{H} N M R\left(\mathrm{CD}_{3} \mathrm{CN}\right)$ and (b) ${ }^{19} \mathrm{~F} N M R\left(\mathrm{CD}_{3} \mathrm{CN}\right)$ of bis(2,2,2-trifluoroethyl) carbonate with $\mathrm{Np}_{1} \mathrm{~F}(0.19 \mathrm{M})$. 


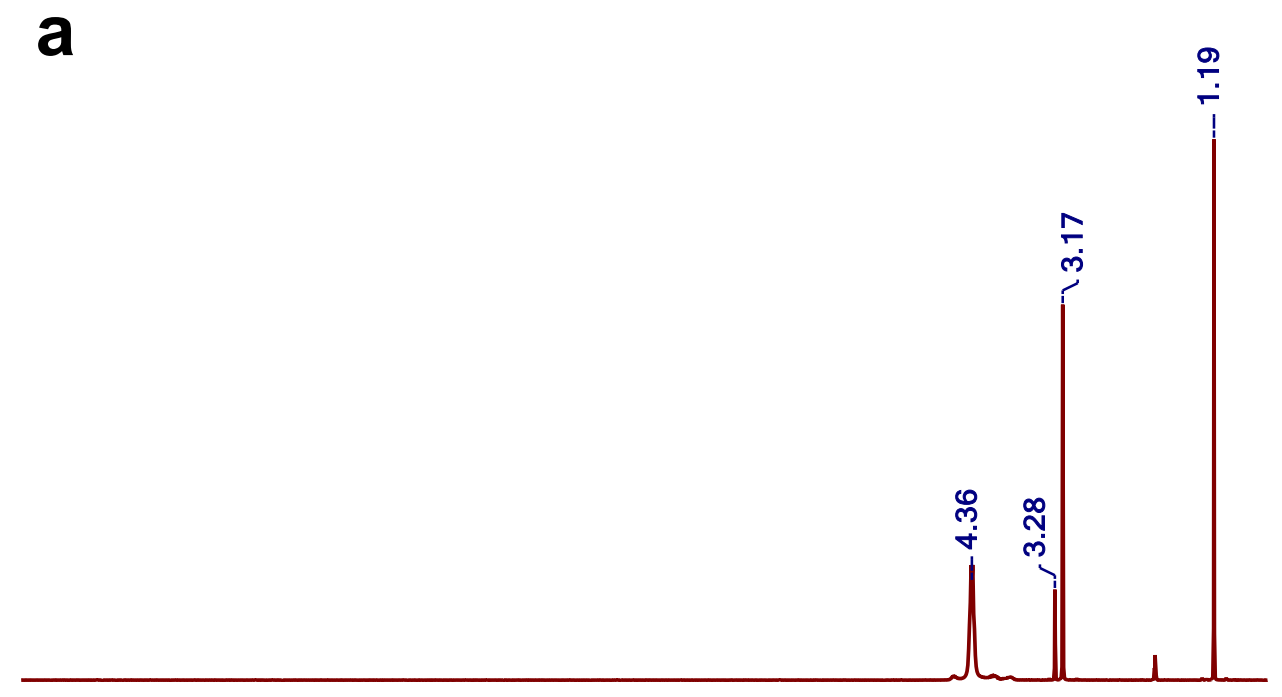

$\begin{array}{llllllllllllllll}16 & 15 & 14 & 13 & 12 & 11 & 10 & \begin{array}{r}9 \\ 14\end{array} & 8 & 7 & 6 & 5 & 4 & 3 & 2 & 1\end{array}$

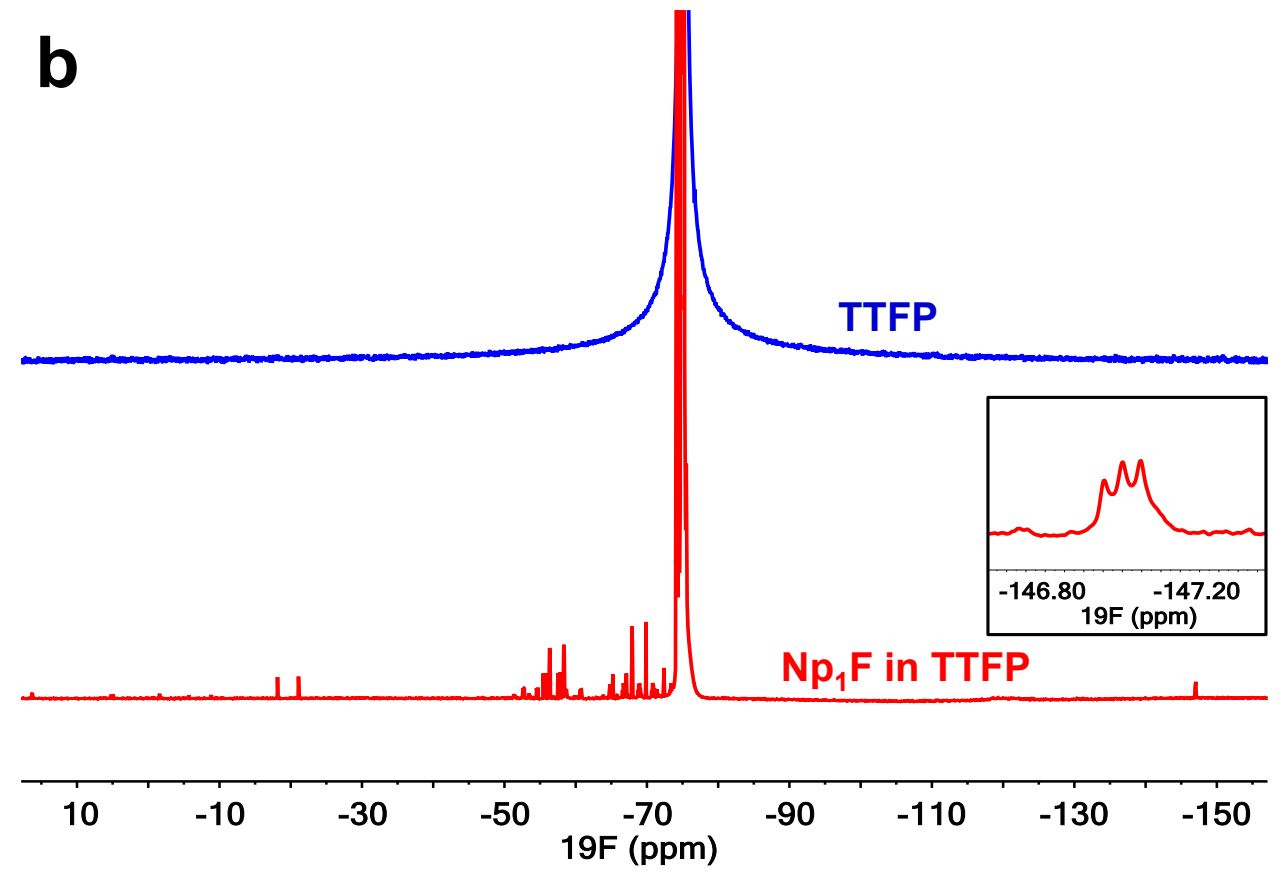

Figure S7. (a) ${ }^{1} \mathrm{H} N M R\left(\mathrm{CD}_{3} \mathrm{CN}\right)$ of tris(2,2,2-trifluoroethyl) phosphite with $\mathrm{Np}_{1} \mathrm{~F}$. (b) ${ }^{19} \mathrm{~F} \mathrm{NMR}$ $\left(\mathrm{CD}_{3} \mathrm{CN}\right)$ of tris(2,2,2-trifluoroethyl) phosphite without $\mathrm{Np}_{1} \mathrm{~F}$ (blue) and tris(2,2,2-trifluoroethyl) phosphite with $\mathrm{Np}_{1} \mathrm{~F}(1.05 \mathrm{M})$ (red). 

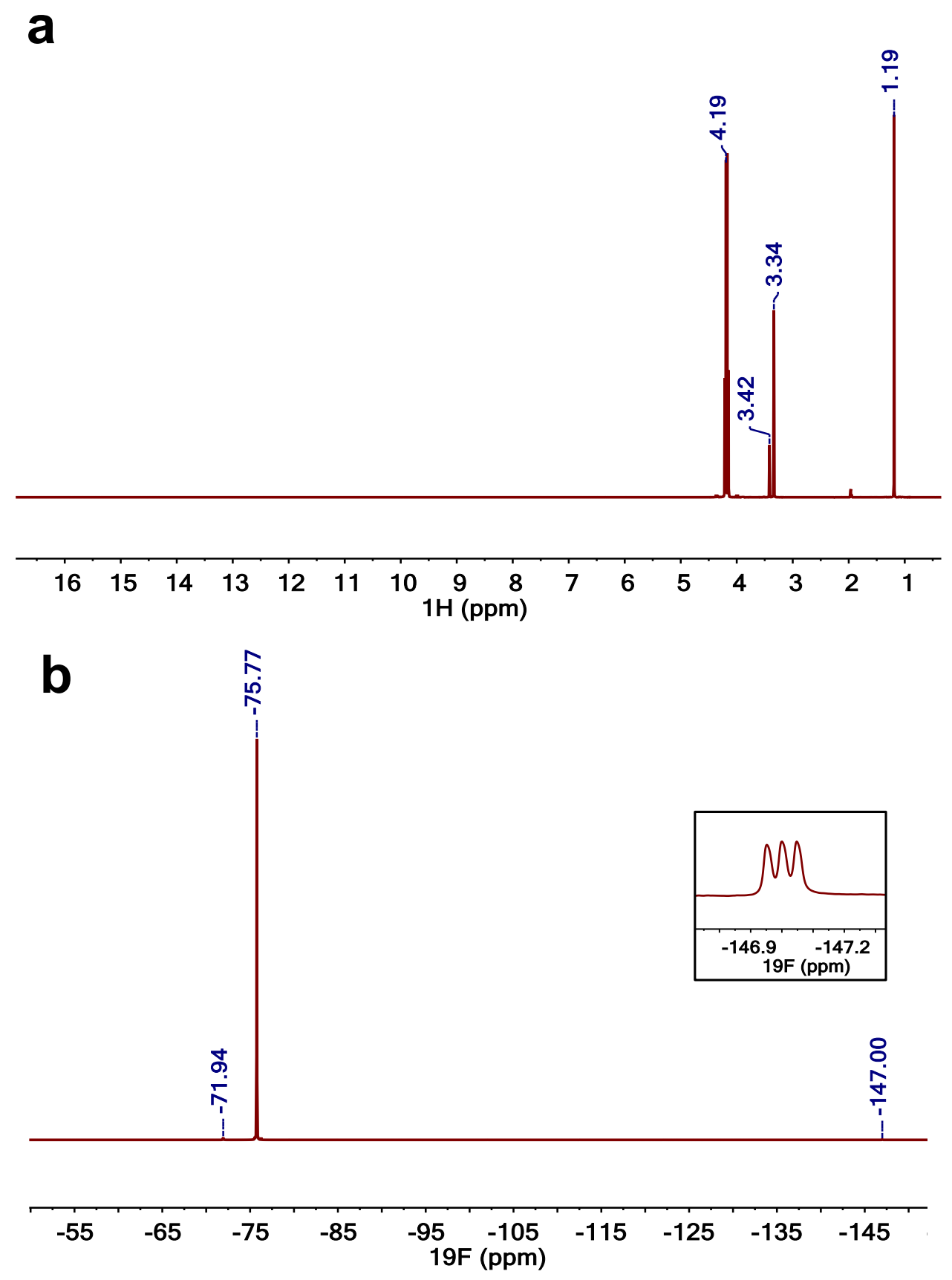

Figure S8. (a) ${ }^{1} \mathrm{H} N M R\left(\mathrm{CD}_{3} \mathrm{CN}\right)$ and (b) ${ }^{19} \mathrm{~F} \mathrm{NMR}\left(\mathrm{CD}_{3} \mathrm{CN}\right)$ of bis(2,2,2-trifluoroethyl) ether with $\mathrm{Np}_{1} \mathrm{~F}(2.23 \mathrm{M})$. 
Table S2. Free energies of solvation for ions in various organic solvents.

\begin{tabular}{|c|c|c|c|c|}
\hline Entry & Solvating Class & Solvent & $\begin{array}{l}\text { Approx. Solubility } \\
\text { (mol Np }{ }_{1} \mathrm{~F} / \\
\text { L solvent) }\end{array}$ & $\begin{array}{l}\text { Sum }-\Delta G_{\mathrm{s}, \mathrm{F}} \\
\text { (kcal/mol) }\end{array}$ \\
\hline 1 & Non-solvating & $\mathrm{F}_{5} \mathrm{BN}$ & 0 & $99.9 \pm 1.8$ \\
\hline 2 & Non-solvating & TFAP & 0 & $109.3 \pm 1.3$ \\
\hline 3 & Non-solvating & $\mathrm{BN}$ & 0 & $111.3 \pm 0.6$ \\
\hline 4 & Weak & PN & 0.07 & $116.6 \pm 0.6$ \\
\hline 5 & Weak & 2-FBN & 0.12 & $117.9 \pm 2.6$ \\
\hline 6 & Weak & $3-F B N$ & 0.19 & $116.3 \pm 1.7$ \\
\hline 7 & Strong & 2,3-FBN & 0.39 & $119.2 \pm 1.1$ \\
\hline 8 & Strong & 2,6-DFP & 0.40 & $119.8 \pm 1.4$ \\
\hline 9 & Very strong & BTFE & 2.23 & $113.5 \pm 1.1$ \\
\hline
\end{tabular}



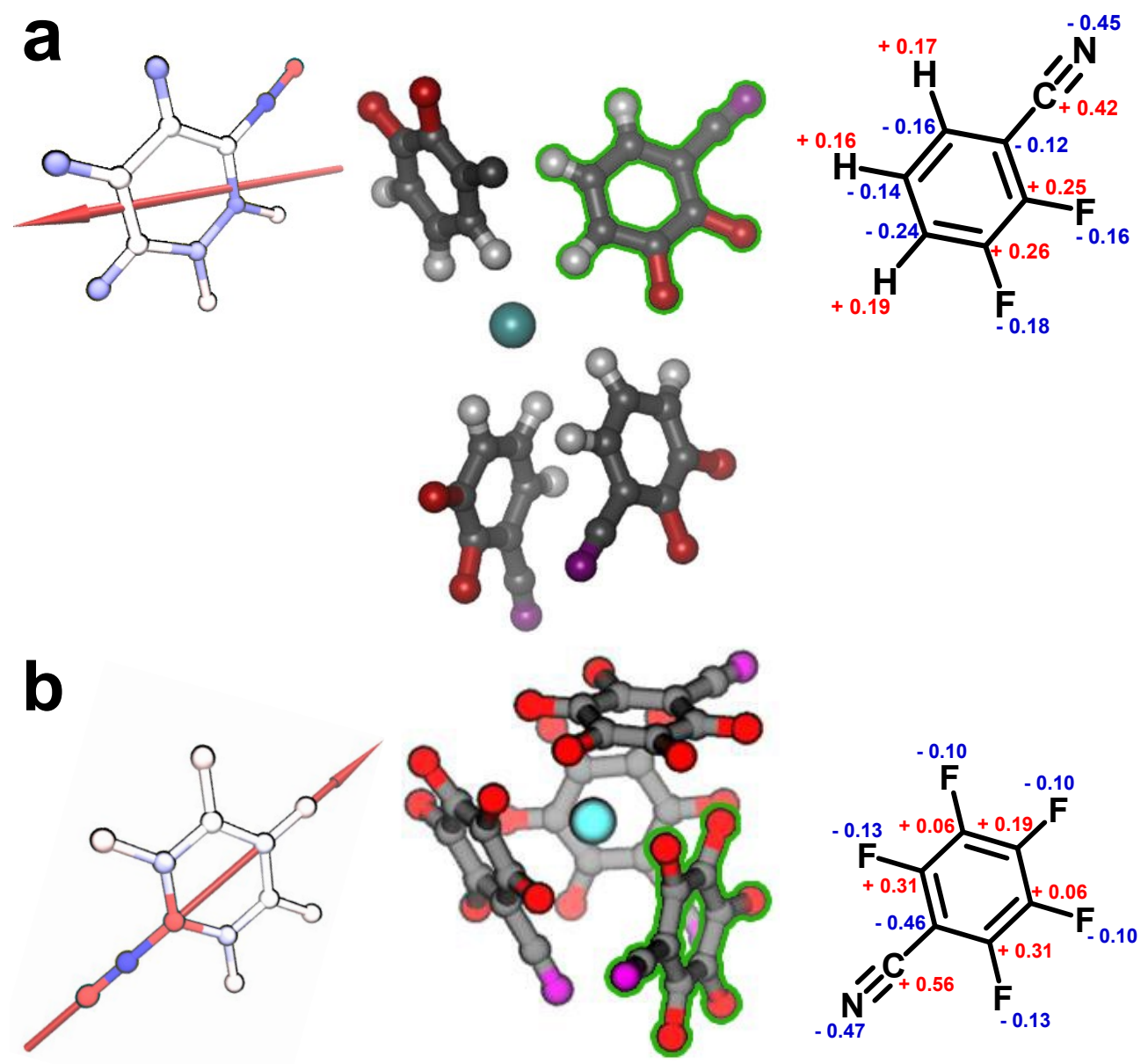

Figure S9. Molecular dynamics simulations for ions in 2,3-FBN and $\mathbf{F}_{5} \mathbf{B N}$. Illustration of solvent properties for (a) 2,3-FBN and (b) $\mathrm{F}_{5} \mathrm{BN}$. The middle image represents a simulated solvation shell of solvent molecules surrounding $\mathrm{F}^{-}$(cyan sphere). The left image shows the dipole orientation of the solvent molecule outlined in green. Vectors are drawn from negative to positive and are not to scale. Dipole magnitudes are $\mu=4.99 \mathrm{D}(2,3-\mathrm{FBN})$ and $\mu=2.87 \mathrm{D}\left(\mathrm{F}_{5} \mathrm{BN}\right)$. The right image shows the partial charge distribution of the solvent molecule oriented in the same direction as the solvent molecule outlined in green. (a) Fluoride ions are solvated by the protons opposite the nitrogen and fluorine atoms. $\mathrm{Np}_{1}{ }^{+}$ions are solvated preferentially by the nitrogen and fluorine atoms. (b) The fluoride ion is coordinated preferentially with the ring carbons, with little fluorine or nitrogen participation. The cyano group dominates the $\mathrm{Np}_{1}{ }^{+}$ solvation environment. 
Table S3. Fluoride-ion solvation sheath of $(\mathrm{BTFE})_{X}-(\mathrm{co} \text {-solvent })_{Y}-\left(\mathrm{Np}_{1}{ }^{+}\right)_{Z}$. Statistical errors for the last digit are indicated in parenthesis.

\begin{tabular}{|l|l|l|l|l|}
\hline & $\mathbf{X}$ & $\mathbf{Y}$ & $\mathbf{Z}$ & $\begin{array}{l}\text { Fraction of } \\
\mathrm{Np}_{1}{ }^{+} \text {-free } \mathbf{F}^{-}, \boldsymbol{\alpha}\end{array}$ \\
\hline $\begin{array}{l}\text { Neat BTFE } \\
\text { (Expt) }\end{array}$ & 2 & - & 1 & 0.087 \\
\hline Neat BTFE & $2.64(8)$ & - & $2.45(8)$ & $0.0022(9)$ \\
\hline BTFE/DMA & $2.17(5)$ & $0.50(2)$ & $2.53(6)$ & $0.082(5)$ \\
\hline BTFE/DMBA & $2.4(2)$ & $0.18(2)$ & $2.3(2)$ & $0.02(3)$ \\
\hline BTFE/pDiox & $2.5(1)$ & $0.59(5)$ & $1.92(5)$ & $0.06(5)$ \\
\hline BTFE/TEA & $1.93(5)$ & $0.026(7)$ & $3.13(7)$ & $0.002(3)$ \\
\hline
\end{tabular}

Table S4. Ion conductivity of mixtures, according to the Green-Kubo and Nernst-Einstein relations. Statistical errors for the last digit are indicated in parenthesis.

\begin{tabular}{|l|l|l|}
\hline & $\sigma_{N E}(\mathbf{m S} / \mathbf{c m})$ & $\sigma_{G K}(\mathbf{m S} / \mathbf{c m})$ \\
\hline Neat BTFE & $4.5(4)$ & $0.4(1)$ \\
\hline BTFE/DMA & $3.9(7)$ & $0.7(3)$ \\
\hline BTFE/DMA (3:2) & $3.4(2)$ & $0.8(2)$ \\
\hline BTFE/DMBA & $3.1(2)$ & $0.4(2)$ \\
\hline BTFE/pDiox & $0.8(1)$ & $0.14(1)$ \\
\hline BTFE/TEA & $3.5(3)$ & $0.16(6)$ \\
\hline
\end{tabular}


a

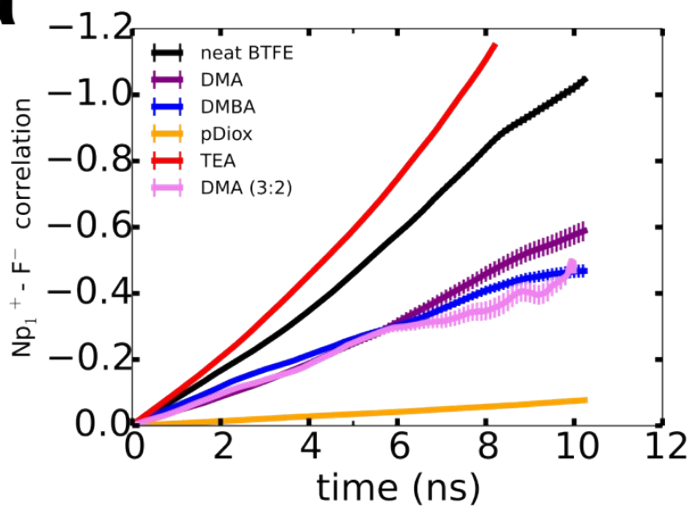

b

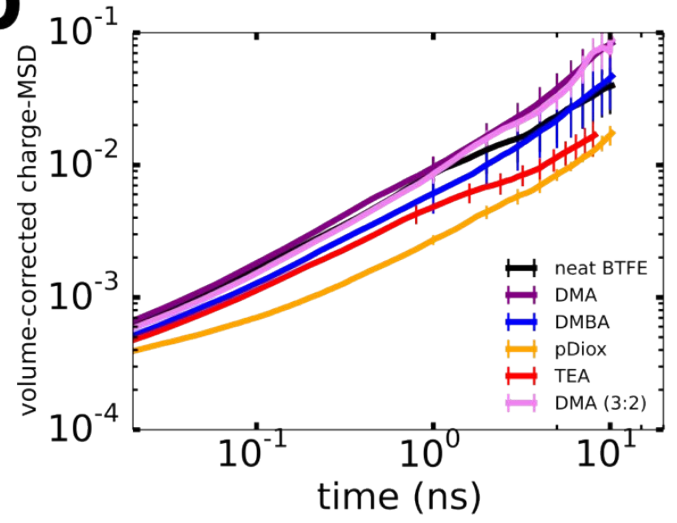

Figure S10. (a) Correlation in displacement between $\mathrm{Np}_{1}{ }^{+}$and $\mathrm{F}^{-}$, $z_{i} z_{j}\left\langle\left[\vec{r}_{i}(t)-\vec{r}_{i}(0)\right]\left[\vec{r}_{j}(t)-\vec{r}_{j}(0)\right]\right\rangle / V$, where $i$ indicates $\mathrm{Np}_{1}{ }^{+}$and $j$ indicates $\mathrm{F}^{-}$.

Volume-corrected charge MSD on a log-log scale, the slope of which indicates calculated ion conductivity.
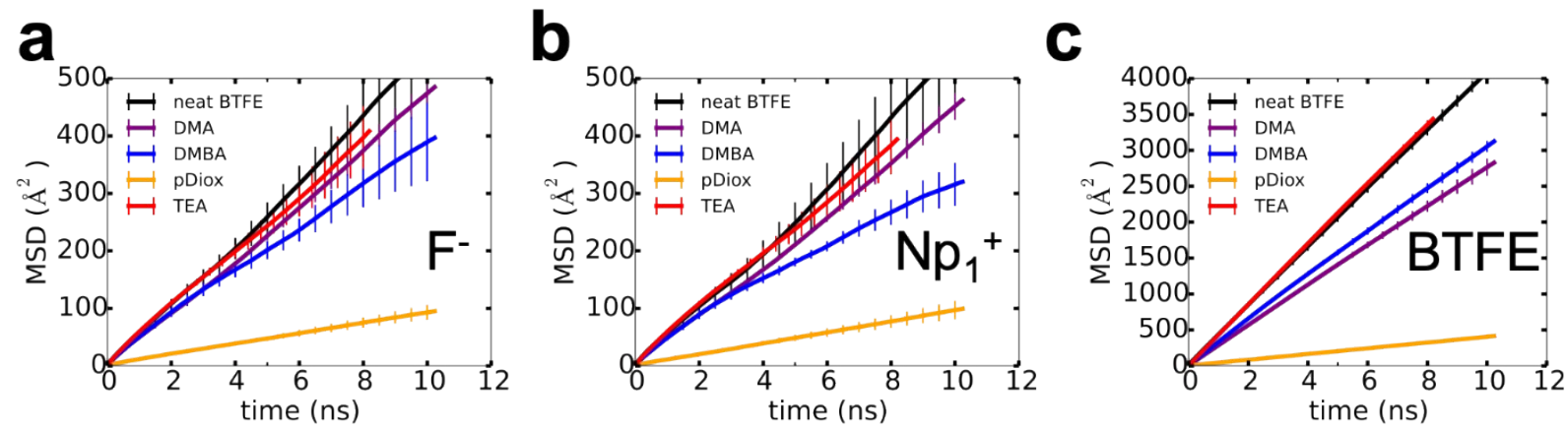

Figure S11. Mean-square displacement of (a) $\mathrm{F}^{-}$, (b) $\mathrm{Np}_{1}{ }^{+}$, and (c) BTFE in a mixture with a cosolvent or neat BTFE solution. 


\section{Mixture Effects on Conductivity}

All-atom molecular dynamics simulations were performed to provide an understanding of the mixture effect on conductivity, with co-solvents including DMA, DMBA, pDiox, and TEA. Following the experiments, $\mathrm{Np}_{1} \mathrm{~F}$ salt concentration is fixed $0.75 \mathrm{M}$, and the volume ratio of BTFE solvent to co-solvent is 3:1 for all simulated mixtures. Analysis of the simulation results provides mechanistic insights into the distinct factors that influence the experimentally observed conductivity, including an increase in the solution viscosity by co-solvent addition and the suppression of ion diffusivity due to ion pairing. It is also clear that accurately capturing the balance between these two effects is essential for the quantitative reproduction of experimental results, which is a difficult challenge for the simple point-charge models employed here. ${ }^{12}$

We begin by analysis of fluoride-ion solvation sheath, composed of BTFE molecules, cosolvent molecules, and $\mathrm{Np}_{1}{ }^{+}$ions. Table $\mathrm{S} 3$ reports the composition of the fluoride-ion solvation sheath in terms of the number of BTFE molecules $(\mathrm{X})$, co-solvent molecules $(\mathrm{Y})$, and $\mathrm{Np}_{1}{ }^{+}$ions $(\mathrm{Z})$ surrounding one fluoride ion in a $0.75 \mathrm{M} \mathrm{Np}_{1} \mathrm{~F} / \mathrm{BTFE}$ :co-solvent (3:1) electrolyte mixture. Molecules or ions are counted as part of the solvation sheath if they provide at least two hydrogens within $3 \AA$ of a single fluoride ion, according to the first peak of radial distribution functions. The fraction of fluoride ions without $\mathrm{Np}_{1}{ }^{+}$ions in the solvation sheath to fluoride ions with $\mathrm{Np}_{1}{ }^{+}$ions in the solvation sheath is also reported in Table S3. This fraction is representative of the degree of ion dissociation, $\alpha$, (see main text). Results show that co-solvent molecules barely participate in solvation of the fluoride-ions, consistent with experimental observations: $100 \%$ co-solvent solutions (without BTFE) did not dissolve the $\mathrm{Np}_{1} \mathrm{~F}$ salt. Similar numbers of $\mathrm{Np}_{1}{ }^{+}$

\footnotetext{
12 (a) A. France-lanord and J. C. Grossman, Phys. Rev. Lett., 2019, 122, 1-6. (b) C. J. Fennell, A. Bizjak, V. Vlachy and K. A. Dill, J. Phys. Chem. B, 2009, 113, 6782-6791. (c) B. M. Savoie, M. A. Webb and T. F. Miller, J. Phys. Chem. Lett., 2017, 8, 641-646.
} 
ions and BTFE molecules in the fluoride ion solvation sheath support that these mixtures are a concentrated solution with ion pairs or small ion aggregates.

We now explore the effect of solution viscosity on the mixture conductivities. Meansquared displacement (MSD) was calculated as a function of time for $\mathrm{F}^{-}$anions, $\mathrm{Np}_{1}{ }^{+}$cations, and BTFE molecules (Fig. S11) and used to obtain the diffusion coefficient as explained above. The inverse of the diffusion coefficient of BTFE was used as a proxy for solution viscosity, according to the Stokes-Einstein relation. ${ }^{13}$ The diffusion coefficient of the mixtures can vary significantly depending on the additive species (Fig. S11C). This change in viscosity suppresses both $\mathrm{Np} 1^{+}$and $\mathrm{F}^{-}$ion self-diffusion in the simulated mixtures (Fig. S11), resulting in decreased ${ }^{\sigma E}$ (Table S4).

We now explore the effect of ion pairing on the mixture conductivities. Fig. S10a presents the correlation in dynamics of $\mathrm{Np}_{1}{ }^{+}$and $\mathrm{F}^{-}$diffusion. Results support the significant role of ion pairing on mixture conductivity, with three of the four mixture conductivities strongly correlated with the degree of ion association. In BTFE:TEA, despite a decrease in the mixture viscosity, ions are mostly present in the form of ion pairs or ion aggregates with a high degree of correlated ion motion, resulting in much lower conductivity.

Fig. S10b shows that the simulated conductivities of all mixtures reproduce the observed experimental trends, with the DMA and DMBA additives enhancing conductivity, and the pDiox and TEA suppressing conductivity. Table S4 shows the essential role of correlation in ion motion in determining mixture conductivity, since the Nernst-Einstein conductivity (which assumes all correlations in ion motion are negligible) fails to predict the experimental trends.

\footnotetext{
13 J. P. Hansen and I. R. McDonald, Theory of Simple Liquids, Academic Press, Inc., London, 2nd edn., 1990.
} 
Taken along with the data in Fig. S11, the data here clarify how the mixture conductivity is determined by a balance between mixture viscosity and ion dissociation. 